\title{
Orienting New Respiratory Therapists Into the Neonatal/Pediatric Environment: A Survey of Educators and Managers
}

\author{
Brian K Walsh RRT-NPS FAARC, Michael A Gentile RRT FAARC, and \\ Barry M Grenier RRT-NPS
}

BACKGROUND: Neonatal/pediatric respiratory care is recognized as a unique and complex area of clinical practice. Despite the substantial effort and costs associated with orienting neonatal/ pediatric practitioners, few data exist related to the process of training respiratory therapists (RTs) in the acute neonatal/pediatric environment. To gain insight into the adequacy of preparation of RTs entering the neonatal/pediatric environment, the length of orientation necessary to achieve a base level of competency, and the methods used to train new neonatal/pediatric practitioners, we surveyed neonatal/pediatric respiratory care educators and managers. METHODS: The invitation to participate in the survey was distributed via e-mail to 1,259 members of the AARC education specialty section and 1,828 members of the AARC managers specialty section. The survey included 15 questions (not including the demographics questions), scored on 5-point Likert scale, and asked about: what type of degree program (associate's degree or bachelor's degree) better prepares new RTs for the neonatal/pediatric environment; experience requirements for orientation of neonatal/ pediatric RTs; the role of simulation in training neonatal/pediatric RTs; and whether the neonatal/ pediatric specialty credentialing exam should be used as a method of competency testing. There were 4 questions regarding simulation (the use of interactive full-body manikins in a realistic patient care environment), orientation times based on experience, and where the majority of the orientation time was spent. RESULTS: We received 251 responses (response rate 8\%). The majority of respondents were either affiliated with or worked for urban, not-for-profit, non-government organizations. Sixty-three percent disagreed that an associate's degree respiratory therapy program, and $42 \%$ disagreed that a bachelor's degree program adequately prepares a new RT to work in the neonatal/pediatric critical care environment immediately after graduation. Seventy-one percent strongly agreed that children's hospital respiratory care departments should have a dedicated respiratory therapy educator. Seventy-six percent agreed that simulation is an effective tool for training RTs for neonatal/pediatric critical care. Sixty-five percent agreed that RTs should be required to take an exam at the end of the orientation period to verify competency. Fifty-nine percent strongly agreed that neonatal/pediatric RTs should have the National Board for Respiratory Care Registered Respiratory Therapist (RRT) credential. CONCLUSIONS: There appears to be a discrepancy in the educational preparation expected prior to entering the acute-care neonatal/ pediatric environment and what training methods are most appropriate and cost-effective for orienting new RTs to this specialized environment. A dedicated respiratory therapy educator is valued. Simulation is considered an effective tool for training RTs and provides training opportunities that otherwise would not be available. The neonatal/pediatric specialty certification exam appears to be recognized as a valid method of determining mastery and verifying competence. Key words: neonatal; pediatric; respiratory care; respiratory therapist; education; training. [Respir Care 2011;56(8):1122-1129. (C) 2011 Daedalus Enterprises] 


\section{Orienting New Respiratory Therapists Into the Neonatal/Pediatric Environment}

\section{Introduction}

Neonatal/pediatric respiratory care is recognized as a unique and complex area of practice, as evidenced by the creation of the Neonatal/pediatric Specialty (NPS) examination and credential by the National Board for Respiratory Care (NBRC, https://www.nbrc.org/Examinations/ NPS.aspx). Respiratory therapists (RTs) work in a growing number of pediatric facilities. The directory of the National Association of Children's Hospitals and Related Institutions (http://www.childrenshospitals.net) lists 228 institutions in the United States that provide pediatric services, including free-standing children's hospitals, children's hospitals within hospitals, and other children's specialty hospitals. Additionally, RTs staff delivery rooms and neonatal intensive care units in 967 facilities. While the number of practicing neonatal/pediatric RTs is currently unknown, the neonatal/pediatric section of the American Association for Respiratory Care (AARC) currently has over 2,000 members and approximately 3,110 practitioners hold the NPS credential (personal communication, 2010, Sherry Milligan, Associate Executive Director, AARC).

Neonatal/pediatric respiratory care encompasses the treatment of a range of patients, from extremely-low-birthweight premature newborns to adolescents with a wide range of cardiorespiratory diseases of diverse etiologies. The care of the neonatal/pediatric patient thus requires mastery of a wide range of knowledge of pediatric anatomy and physiology, disease etiology and pharmacology, and diagnostic and therapeutic equipment and procedures. Respiratory therapy education programs are required to cover basic neonatal/pediatric care, and neonatal/pediatric content is included on the NBRC entry-level and advanced practitioners credentialing exams. Yet much of the training of neonatal/pediatric practitioners is done on the job. The variety and complexity of the neonatal/pediatric environment require substantial orientation of new staff to meet the requirements of basic competency: the delivery of care safely and effectively. Institutions have developed programs such as internships and apprenticeships to help transition new staff to neonatal/pediatric practice. The training

Mr Walsh is affiliated with the Respiratory Care Department, Children's Medical Center, Dallas, Texas. Mr Gentile is affiliated with the Division of Critical Care, Duke University Medical Center, Durham, North Carolina. Mr Grenier is affiliated with the Department of Respiratory Care, Children's Hospital Boston, Boston, Massachusetts.

The authors have disclosed no conflicts of interest.

Correspondence: Brian K Walsh RRT-NPS, Respiratory Care Department, C6306, Children's Medical Center, 1935 Medical District Drive, Dallas TX 75235. E-mail: brian.walsh@childrens.com.

DOI: $10.4187 /$ respcare.00972

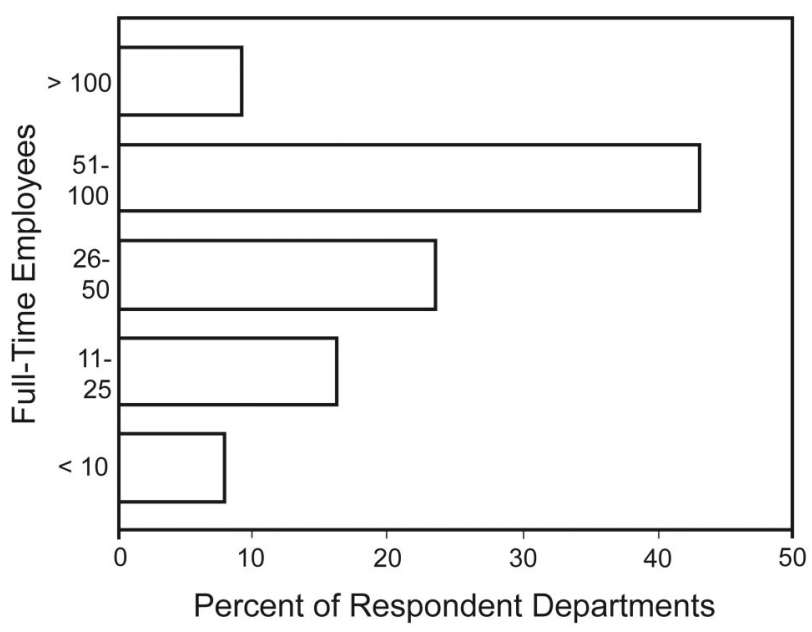

Fig. 1. Survey respondents' respiratory care department sizes

of any new staff, therefore, involves substantial costs, both in fiscal terms and in the strain on staff charged with orientation.

Clinical training, both in schools and in the workplace, has traditionally relied on the apprenticeship model. However, a lack of available clinical sites is a major obstacle to training RTs, ${ }^{1}$ and this lack is all the more acute in neonatal/pediatric practice because of the relatively small number of pediatric care facilities and procedures. Moreover, practicing on patients without having achieved some minimal level of competency is no longer considered acceptable. Non-traditional methods of training, such as highfidelity simulation (the use of interactive full-body manikins in a realistic patient care environment), are being proposed to increase training opportunities in pediatric care. ${ }^{2}$

Despite the substantial effort and costs associated with orienting neonatal/pediatric RTs, few data exist on the process of training RTs in the acute-care environment, and comparisons between institutions remain largely anecdotal. We conducted a survey of respiratory therapy educators and managers in order to gain insight into the adequacy of preparation of RTs entering the neonatal/pediatric environment, the length of orientation necessary to achieve a base level of competency, and the methods used to train new neonatal/pediatric RTs.

\section{Methods}

We surveyed respiratory therapy educators in academic institutions and educators and managers in hospital-based respiratory care departments. We developed a 15-question (excluding demographics), internet-based survey that was approved by the AARC Board of Directors and the Children's Hospital Boston Institutional Review Board. The questionnaire addressed topics and issues that we and RTs 


\section{Orienting New Respiratory Therapists Into the NeOnatal/Pediatric Environment}

Table 1. Survey Questions

Core Questions

Associate's degree respiratory therapy program graduates are adequately prepared to work in the level III neonatal/pediatric critical care environment immediately after graduation.

Bachelor's degree respiratory therapy program graduates are adequately prepared to work in the level III neonatal/pediatric critical care environment immediately after graduation.

Bachelor's degree respiratory therapy program curricula should include a neonatal/pediatric specialty track.

Children's hospital respiratory care departments should have a dedicated respiratory therapy educator.

Respiratory care departments in non-children's hospitals with neonatal and/or pediatric ICUs should have a dedicated pediatric respiratory therapy educator.

Educational functions of pediatric respiratory therapists are best performed by supervisors and senior staff.

High-fidelity medical simulation is an effective tool in the training of respiratory therapists for neonatal/pediatric critical care.

The costs and logistics of high-fidelity medical simulation outweigh its benefits in the training of pediatric respiratory therapists.

High-fidelity medical simulation offers neonatal/pediatric training opportunities that would not otherwise be available to respiratory therapists.

Neonatal/pediatric respiratory therapists should be required to take a written exam at the end of orientation to be deemed competent.

The neonatal/pediatric therapist should be an RRT.

The NBRC NPS credential can be utilized during the orientation process to establish the basic core understanding.

Neonatal/pediatric respiratory therapists should become NPS credentialed.

Multiple-Choice Questions

High-fidelity medical simulation is used as a tool in the training of neonatal/pediatric respiratory care in my institution. No. Yes. Not Applicable.

The following best reflects the average orientation time necessary for respiratory therapists without neonatal/pediatric experience to gain clinical competency in all areas of neonatal/pediatric critical care. 4 weeks. 2 months. 3-4 months. 4-6 months. $>6$ months.

The following best reflects the average orientation time necessary for respiratory therapists with neonatal/pediatric experience to gain clinical competency in all areas of neonatal/pediatric critical care. 4 weeks. 2 months. 3-4 months. 4-6 months. > 6 months.

During orientation of the neonatal/pediatric respiratory therapist, where is the majority of the time spent? Aerosol or drug therapy. Anatomy and physiology. Mechanical ventilation. Airway management.

RRT $=$ Registered Respiratory Therapist

NBRC $=$ National Board for Respiratory Care

NPS $=$ Neonatal/Pediatric Specialty

in our institutions identified as having national applicability, based on our review of our own experience with orienting new RTs and feedback from the AARC Board of Directors. The questionnaire underwent one round of pilot testing with 5 RTs and a feedback session with us. The invitation to participate in the survey was distributed via e-mail to 1,259 members of the AARC education specialty section and 1,828 members of the AARC managers specialty section. The invitation e-mail included a link to the web-based survey, at http://www.SurveyMonkey.com. The survey was available for the 3 -week period prior to the AARC Summer Forum. The purpose of the survey was to characterize the respondents' opinions of what types of education programs, education methods, and length of orientation adequately prepare a new RT for the neonatal/ pediatric environment.

The survey had 3 sections:

- Respondent demographic and professional data, including size, location, affiliation, and type of hospital, and number of full-time employees in the respondent's respiratory therapy department.

- Level of agreement (measured on a 5-point Likert scale of 1 [strongly disagree] to 5 [strongly agree]) with 13 state- ments about neonatal/pediatric RT education (Table 1).

- Four multiple-choice questions on medical simulation, time required for neonatal/pediatric RT orientation, and on what subjects the majority of the RT's orientation time is spent: aerosol/drug therapy, anatomy and physiology, mechanical ventilation, or airway management.

\section{Results}

\section{Demographics}

We received 251 responses ( $8 \%$ response rate), of which $85 \%$ were from respiratory care hospital department managers. The majority of the respondents were either affiliated with or worked for urban, not-for-profit, non-government organizations. Forty-eight percent of the respondents were affiliated with a medical school. Eighty-three percent of the hospitals were not considered primary children's hospitals. The respondents' average hospital size was 427 beds, with an average daily census of 342 patients. Fifty-two percent of the respondent departments had a full-time employee count greater than 50 (Fig. 1) 


\section{Orienting New Respiratory Therapists Into the Neonatal/Pediatric Environment}

\section{Core Questions}

Figure 2 summarizes the responses to the Likert-scale core questions.

Educational Preparation. Sixty-three percent of respondents disagreed that an associate degree respiratory therapy program adequately prepares the student to work in the neonatal/pediatric critical care environment immediately after graduation, whereas $42 \%$ disagreed that a bachelor's degree program adequately prepares the student to work in neonatal/pediatrics, and $36 \%$ agreed, and $22 \%$ were neutral. Ninety-three percent agreed, and $71 \%$ strongly agreed, that respiratory therapy bachelor's degree programs should offer a neonatal/pediatric specialty track.

Orientation. Seventy-one percent strongly agreed that a children's hospital respiratory care department should have a dedicated RT educator. Seventy-one percent somewhat or strongly agreed that a respiratory care department in a non-children's hospital that has a neonatal and/or pediatric ICU should have a dedicated pediatric RT educator. Only $46 \%$ somewhat or strongly agreed that the RT-education functions of a children's hospital respiratory care department are best performed by supervisors and senior staff. Forty-nine percent of respondents felt that the average length of orientation for RTs without neonatal/pediatric experience should be $\geq 4$ months, where as $69 \%$ of respondents felt that RTs with previous neonatal/pediatric experience require $\leq 2$ months of orientation (Fig. 3). During orientation the majority of time was dedicated to mechanical ventilation (79\%), followed by airway management (13\%), anatomy and physiology (5\%), and aerosol or drug therapy (3\%).

High-Fidelity Medical Simulation. Seventy-six percent of the respondents agreed that high-fidelity simulation is an effective tool for training RTs for neonatal/pediatric critical care, but the majority of the respondents were neutral when asked if the associated cost outweighs the benefits. Seventy-five percent agreed that simulation offers training opportunities that otherwise would not be available to RTs, but $66 \%$ were not using high-fidelity simulation in the training of neonatal/pediatric RTs.

Testing. Sixty-five percent agreed that RTs should be required to take an exam at the end of neonatal/pediatric orientation to be deemed competent. Fifty-nine percent strongly agreed that neonatal/pediatric RTs should have the Registered Respiratory Therapist (RRT) credential from the NBRC. Seventy percent agreed that the NBRC NPS credential could be used to validate achievement of the basic core competencies after the orientation period. Eighty- six percent agreed, and $61 \%$ strongly agreed, that neonatal/pediatric RTs should become NPS credentialed.

\section{Multiple-Choice Questions}

Table 2 shows the responses to the multiple-choice questions.

\section{Discussion}

The intent of our survey was to gain insight into the orientation requirements of RTs new to the neonatal/pediatric acute care environment from the perspective of educators and managers responsible for the training process. Our primary goal was to quantify the time to adequately train new neonatal/pediatric RTs. Seventy-three percent stated the average orientation time was $\geq 3$ months, and $29 \%$ indicated the average orientation time was $\geq 6$ months. Not surprisingly, this contrasts greatly with the length of orientation the respondents deemed necessary for practitioners with neonatal/pediatric experience to reach clinical competency. These results are consistent with anecdotal evidence of lengthy orientation in pediatric facilities, and may help explain the emergence of extensive and prolonged pediatric training programs that have been formalized as "internships" and "apprenticeships." We did not query to determine the proportion of new RTs entering clinical practice with and without neonatal/pediatric experience. However, it is our experience that only a very small proportion of our new employees come to us with neonatal/pediatric critical care experience; if this is true in other institutions, the great majority of department resources are being spent orienting staff naïve to neonatal/pediatric respiratory care.

It is difficult to compare the orientation times found in our survey to those in other areas of respiratory care practice. The 2009 AARC human resources survey indicated that the overall average time spent orienting new RTs in acute care hospitals is 3-4 weeks, depending on whether the median hours (120) or mean hours (156) is used as the standard (personal communication, 2010, William Dubbs, Director of Management and Education, AARC). The AARC human resources survey found a wide range of responses, from 16 to 600 hours. It is not possible to differentiate the orientation time for neonatal/pediatric facilities in the AARC data. However, it is notable that $49 \%$ of the orientation times found in our survey were equal to or greater than the longest orientation time found in the AARC survey. One possible explanation for this apparent discrepancy is that different interpretations of "orientation" were inferred in the surveys. For example, the term orientation might have been interpreted by some to indicate only the period of time when the orientee works under the direct supervision of a preceptor, whereas some may 


\section{Orienting New Respiratory Therapists Into the Neonatal/Pediatric Environment}

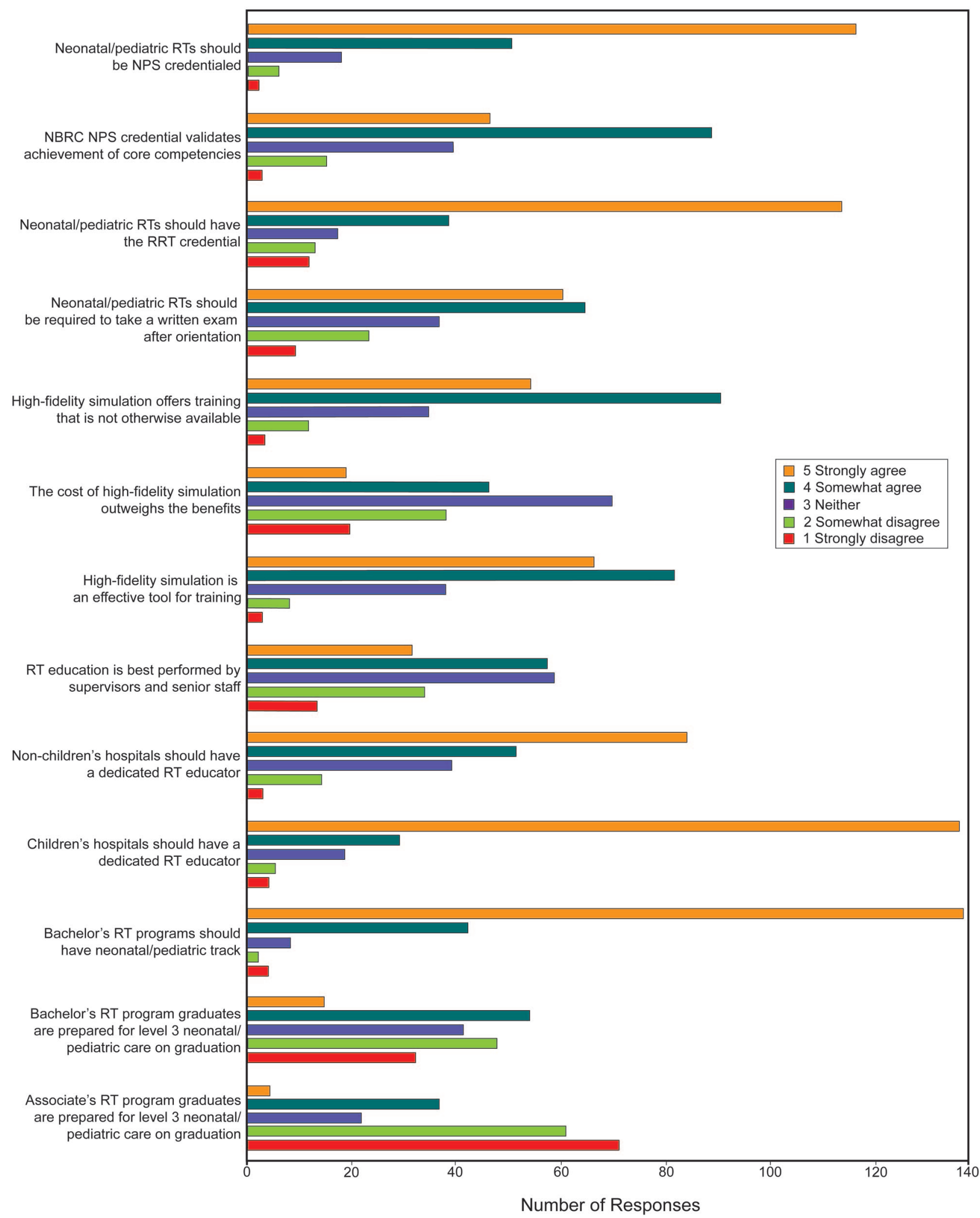

Fig. 2. Responses to the survey's 13 core questions. RT = respiratory therapist. NBRC $=$ National Board for Respiratory Care. RRT $=$ Registered Respiratory Therapist. 


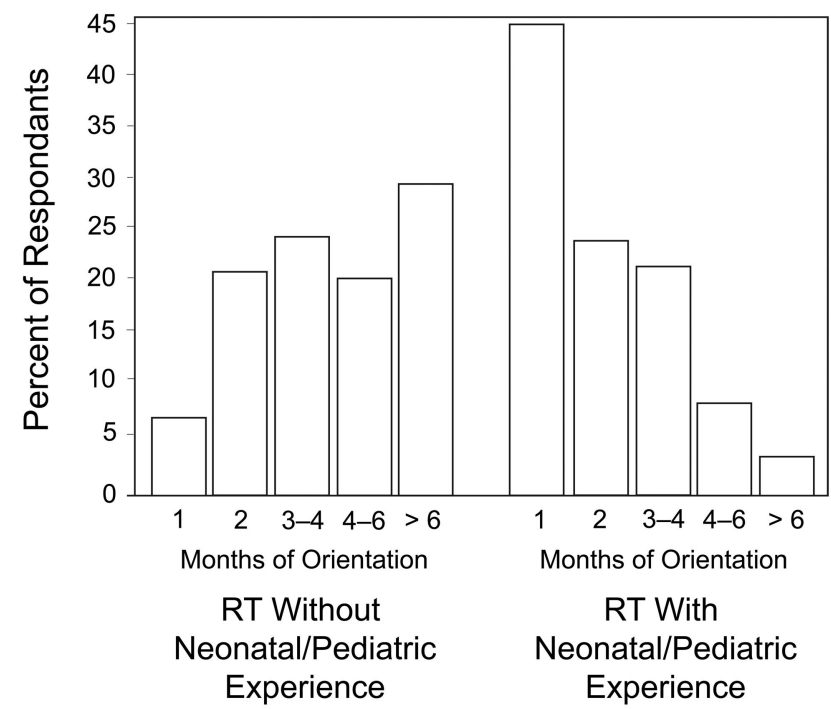

Fig. 3. Respondents' opinions on the length of orientation required for respiratory therapists (RTs), with and without neonatal/pediatric experience, to practice in a level III neonatal/pediatric acute care environment.

have seen orientation as including indirect supervision. Furthermore, our survey specifically asked for the orientation time necessary to gain clinical competency in all areas of neonatal/pediatric critical care. Though a basic level of competency is an implied end-point of the orientation process, the term competency may not have been a clear definition of orientation used by our respondents. Similarly, the inclusion of critical care in our definition may also have influenced our responses. We specified critical care in our definition because critical care consumes such a large part of neonatal/pediatric respiratory care practice. This notion may be supported by the finding that over $90 \%$ of respondents indicated that the majority of orientation time was devoted to either airway management or mechanical ventilation.

The considerable length of orientation found in our survey holds striking implications for the human and financial resources required to orient new staff to the neonatal/ pediatric respiratory care environment. In a study of the financial impact of turnover among RTs, Stoller et al estimated the cost of training in one hospital in their healthcare system at $\$ 3,447$ per staff member. ${ }^{3}$ That study was reported in 2001, and the cost was based on a 17-day (approximately 3.5 "work weeks") training schedule. While Stoller et al cautioned that their particular cost estimate reflected only one institution and was not generalizable, adjusting to 2010 dollars and an orientation period of up to 6 months or more suggests that neonatal/pediatric RT orientation may incur substantial cost. Stoller et al also pointed to the substantial expense associated with employee turnover. ${ }^{3}$ It is quite possible that high turnover might be a "hidden" additional cost of not providing adequate orien- tation and training in a complex and specialized healthcare environment such as neonatal/pediatric acute care.

It seems self-evident that an important determinant of success in, and ease of transition into, the neonatal/pediatric respiratory care environment is adequate educational preparation. Our results suggest the managers and educators surveyed perceived a substantial lack of preparation in new RTs for neonatal/pediatric care. When asked if associate's degree program graduates are adequately prepared to work in level III neonatal/pediatric critical care environment immediately after graduation, only $21 \%$ of respondents strongly agreed or somewhat agreed, whereas $68 \%$ either somewhat or strongly disagreed. Thirty-six percent of respondents indicated that bachelor's degree RT graduates are adequately prepared for the neonatal/pediatric critical care environment. It is notable that such a large percentage of respondents that that neither bachelor's nor associate's degree students are prepared to immediately work in the neonatal/pediatric critical care environment. A lack of adequate preparation for clinical practice might, at least partly, explain the long orientation period the respondents deemed necessary to prepare neonatal/pediatric RTs.

While our survey did not specifically ask if neonatal/ pediatric managers and educators preferred hiring bachelor's degree versus associate's degree graduates, our results suggest that managers might have a preference for hiring bachelor's degree graduates if there is a perceived difference in the quantity of their preparation. This would seem to contradict a recent survey of respiratory care managers that indicated that they did not prefer hiring bachelor's degree graduates over associate's degree graduates. ${ }^{4}$ That study surveyed managers in all domains of respiratory care and did not distinguish neonatal/pediatric from other areas of practice.

Our respondents' perception of a general lack of preparation of new RT graduates for neonatal/pediatric respiratory care might be explained by gaps in learning at the program level. While all respiratory therapy education programs are required to cover neonatal/pediatric care content, the curricula and faculty background differ greatly from program to program. As an example, a recent study of neonatal resuscitation education in respiratory therapy education programs found only about $57 \%$ of the faculty teaching neonatal resuscitation courses were neonatal resuscitation program certified, and only $51 \%$ held the NPS credential. ${ }^{5}$ In that survey the most frequently cited reason for lack of emphasis on neonatal resuscitation training was curriculum time restrictions. It is possible that insufficient clinical experience might also relate to the perceived lack of preparation found in our survey. In the survey of neonatal resuscitation program training the average amount of time allotted for neonatal/pediatric clinical experience was 90 hours. ${ }^{5}$ It is our experience that the clinical exposure to 


\section{Orienting New Respiratory Therapists Into the Neonatal/Pediatric Environment}

Table 2. Responses to the Multiple-Choice Questions

\begin{tabular}{|c|c|c|c|}
\hline Question & $\begin{array}{l}\text { Number of } \\
\text { Responses }\end{array}$ & Answer & $\begin{array}{r}\text { Percent of } \\
\text { Respondents }\end{array}$ \\
\hline $\begin{array}{l}\text { High-fidelity medical simulation is used as a tool in the training of } \\
\text { neonatal/pediatric respiratory care in my institution. }\end{array}$ & 196 & $\begin{array}{l}\text { No } \\
\text { Yes } \\
\text { Not applicable }\end{array}$ & $\begin{array}{r}26 \\
66 \\
8\end{array}$ \\
\hline $\begin{array}{l}\text { The following best reflects the average orientation time necessary for } \\
\text { respiratory therapists without neonatal/pediatric experience to gain } \\
\text { clinical competency in all areas of neonatal/pediatric critical care. }\end{array}$ & 195 & $\begin{array}{l}4 \text { weeks } \\
2 \text { months } \\
3-4 \text { months } \\
4-6 \text { months } \\
>6 \text { months }\end{array}$ & $\begin{array}{r}6 \\
21 \\
24 \\
20 \\
29\end{array}$ \\
\hline $\begin{array}{l}\text { The following best reflects the average orientation time necessary for } \\
\text { respiratory therapists with neonatal/pediatric experience to gain } \\
\text { clinical competency in all areas of neonatal/pediatric critical care. }\end{array}$ & 194 & $\begin{array}{l}4 \text { weeks } \\
2 \text { months } \\
3-4 \text { months } \\
4-6 \text { months } \\
>6 \text { months }\end{array}$ & $\begin{array}{c}45 \\
24 \\
21 \\
8 \\
3 *\end{array}$ \\
\hline $\begin{array}{l}\text { During orientation of the neonatal/pediatric respiratory therapist, } \\
\text { where is the majority of the time spent? }\end{array}$ & 192 & $\begin{array}{l}\text { Aerosol or drug therapy } \\
\text { Anatomy and physiology } \\
\text { Mechanical ventilation } \\
\text { Airway management }\end{array}$ & $\begin{array}{r}3 \\
5 \\
79 \\
13\end{array}$ \\
\hline
\end{tabular}

neonatal/pediatric patients, especially critically ill patients, can be quite limited and may be mostly observational.

Opportunities for neonatal/pediatric clinical experience may be less available to RT students due to the relatively small number of neonatal/pediatric patients versus adult patients. According to the Agency for Healthcare Research and Quality, in 2000, children and adolescents accounted for $13 \%$ of all days spent in the hospital in the United States. ${ }^{6}$ The relatively small neonatal/pediatric patient population may also influence the allocation of resources by RT education programs. Training programs may be unwilling or unable to devote limited training resources to the small percentage of their students who will ultimately work in neonatal/pediatric practice.

Our respondents' perceived discrepancy in readiness between associate's degree and bachelor's degree graduates for neonatal/pediatric critical care may also point to a difference in the breadth of respiratory care knowledge between bachelor's degree and associate's degree students. Recently, Taliercio et al found that bachelor's degree graduates had a higher knowledge score for alpha- 1 antitrypsin than did their associate's degree counterparts. ${ }^{7}$ That study found a generally low level of alpha- 1 antitrypsin knowledge, regardless of education level or profession.

Ninety-three percent of our respondents agreed, and $71 \%$ strongly agreed, that bachelor's degree programs should offer a neonatal/pediatric specialty track. This may further reflect our respondents' perceptions about the level of preparation of new respiratory therapy graduates and the ex- penses and resource utilization associated with training new RTs. The responses to this question may also relate to a perceived lack of standardization in the neonatal/pediatric curriculum.

Though specialty track was not defined in the survey question, the term suggests a formal course of advanced training in a specialty area, with some minimum curricular requirements, including didactic, laboratory, and clinical components. It is intriguing to envision a specialty track modeled on the polysomnographic technology specialty course, with curriculum requirements defined by the Committee on Accreditation for Respiratory Care, which is being integrated into both bachelor's degree and associate's degree programs throughout the country. A neonatal/ pediatric specialty track might be a cost-effective way for education programs to provide comprehensive training to the small number of students who will make neonatal/ pediatric respiratory care a career. The success of this type of specialty track would depend heavily on the support of pediatric healthcare facilities, but we think it is likely that these facilities would be more willing to give the necessary support to students committed enough to pursue a specialty track program.

Our respondents placed a high value on attainment of advanced credentials and certification. A sizable percentage agreed that neonatal/pediatric practitioners should hold the RRT credential and the NPS credential. Further, a high percentage thought that the NPS credentialing exam can be used as a measure of core knowledge after orientation. 
While the medical outcomes of patients receiving specialty procedures are linked to the volume of procedures performed by the hospital, ${ }^{8}$ the opportunities for training experiences, especially critical events, are relatively rare in pediatrics. High-fidelity simulation has been proposed as one solution to this so-called "pediatric training paradox." 2 While high-fidelity simulation is being used to train RTs, ${ }^{2,9}$ our survey found that its use in training pediatric RTs is still relatively rare. Greater than $75 \%$ of respondents perceived high-fidelity simulation as an effective tool for training neonatal/pediatric RTs, and a similar percentage agreed that it offers training opportunities that would not otherwise be available. Still, only $26 \%$ reported the use high-fidelity simulation in their institutions. It is possible that our manager-dominated sampling more accurately reflects the degree of high-fidelity simulation use in the hospital setting, where cost and logistics may make high-fidelity simulation less available, and understates the use of high-fidelity simulation in school-based training. A third of our respondents indicated that the cost and logistics of high-fidelity simulation outweigh its training benefits, whereas slightly less disagreed. The large percentage of respondents who neither agreed nor disagreed may reflect a lack of first-hand experience with the technology in their institutions and a lack of impetus to do even a cursory cost/benefit analysis.

\section{Limitations}

Our survey was designed to provide information that would provoke thought and discussion in a forum for educators and managers, and not as a scientific sampling. The vast majority of respondents were mangers, versus educators, so our results are skewed to the management perspective. However, our data may offer some insight into the neonatal/pediatric orientation process and may help guide more formal research in this area.

\section{Conclusions}

It is clear that the need for qualified and competent RTs in the neonatal/pediatric arena is growing. Yet our survey suggests that newly graduated RTs are generally considered inadequately prepared to immediately begin working in this unique and complex environment, that considerable resources are being devoted to the training of neonatal/ pediatric RTs in the workplace, and that dedicated neonatal/pediatric respiratory care educators are warranted. Our data suggest that alterations at the respiratory therapy program level, including the creation of a neonatal/pediatric specialty track, may be needed to adequately prepare the 21 st century neonatal/pediatric RT and help offset the specialty education that is occurring at the institutions of employment. While our respondents recognize high-fidelity simulation as an effective tool for training and for increasing training opportunities, this tool does not appear to be widely utilized for neonatal/pediatric training or competency assessment. At the same time, traditional testing, including the NPS credentialing exam, is considered a valid method of determining core understanding and competency after orientation.

\section{REFERENCES}

1. Kacmarek RM, Durbin CG, Barnes TA, Kageler WV, Walton JR, O'Neil EH. Creating a vision for respiratory care in 2015 and beyond. Respir Care 2009;54(3):375-389.

2. Weinstock PH, Kappus LJ, Kleinman ME, Grenier B, Hickey P, Burns JP. Toward a new paradigm in hospital-based pediatric education: the development of an onsite simulator program. Pediatr Crit Care Med 2005;6(6):635-641.

3. Stoller JK, Orens DK, Kester L. The impact of turnover among respiratory care practitioners in a health care system: frequency and associated costs. Respir Care 2001;46(3):238-242.

4. Becker EA. Respiratory care managers' preferences regarding baccalaureate and master's degree education for respiratory therapists. Respir Care 2003;48(9):840-858.

5. Stickland SL. Does neonatal education get a failing grade? Respir Care Educ Annu 2004;13(Fall):29-35.

6. Agency for Healthcare Research and Quality. Care of children and adolescents in US hospitals. http://www.ahrq.gov/data/hcup/factbk4/ factbk4.htm. Accessed May 23, 2011.

7. Taliercio RM, Chatburn RL, Stoller JK. Knowledge of alpha-1 antitrypsin deficiency among internal medicine house officers and respiratory therapists: results of a survey. Respir Care 2010;55(3):322327.

8. Halm EA, Lee C, Chassin MR. Is volume related to outcome in health care? A systematic review and methodologic critique of the literature. Ann Intern Med 2002;137(6):511-520.

9. Tuttle RP, Cohen MH, Augustine AJ, Novotny DF, Delgado E, Dongilli TA, et al. Utilizing simulation technology for competency skills assessment and a comparison of traditional methods of training to simulation-based training. Respir Care 2007;52(3):263-270. 